\title{
Price Contagion through Balance Sheet Linkages
}

\author{
Agostino Capponi \\ Industrial Engineering and Operations Research Department, \\ Columbia University
}

\author{
Martin Larsson \\ Department of Mathematics, ETH Zurich
}

\begin{abstract}
We study price linkages between assets held by financial institutions that maintain fixed capital structures over time. Firms in the banking sector manage their leverage ratios to conform to prespecified levels. Our analysis suggests that regulatory policies aimed at stabilizing the system by imposing capital constraints on banks may have unintended consequences: banks' deleveraging activities may amplify asset return shocks and lead to large fluctuations in realized returns. The same mechanism can cause spillover effects, where assets held by leverage targeting banks can experience hikes or drops caused by shocks to otherwise unrelated assets held by the same banks. (JEL G10, G12, G21, G38)
\end{abstract}

\section{Introduction}

In this paper we study price linkages arising when otherwise unrelated financial firms, which happen to hold the same assets on their balance sheets, maintain fixed capital structures over time. When an entity enters financial distress, it may be forced to liquidate some of its assets, thereby transmitting negative shocks to other entities holding the same assets. If sufficiently many firms carry out the liquidation simultaneously, this will lead to a selfreinforcing mechanism causing further price drops, which in turn may force other firms to liquidate so as to maintain their target leverage.

\footnotetext{
We are grateful for the comments from Federico Bandi, Darrell Duffie, Rüdiger Fahlenbrach, and Robin Greenwood. We would also like to thank the seminar participants at the following conferences: "2013 Financial Stability Analysis: Using the Tools, Finding the Data," the "BU Mathematical Finance: Conference on Credit Risk and Systemic Risk," and the "2014 Financial Stability Conference: Measurement Challenges in Macroprudential Policy Implementation." We are grateful to the seminar participants at the Stanford Center for Financial and Risk Analytics, and the Linde Institute/Social and Information Sciences Laboratory Seminar Series at Caltech. We would also like to thank an anonymous referee and Maureen O'Hara (the editor) for constructive comments and suggestions. Agostino Capponi gratefully acknowledges the Institute for New Economic Thinking (INET), who supported this research under (IN013-00015). Martin Larsson gratefully acknowledges support from the European Research Council under the European Union's Seventh Framework Programme (FP/2007-2013) / ERC Grant Agreement (307465-POLYTE). Send correspondence to Agostino Capponi, Industrial Engineering and Operations Research Department, Columbia University, New York, NY 10027. E-mail: ac3827@ columbia.edu.
}

(C) The Author 2015. Published by Oxford University Press on behalf of The Society for Financial Studies. All rights reserved. For Permissions, please email: journals.permissions@oup.com doi:10.1093/rapstu/rav006 Advance Access publication July 30, 2015 
The spread of distress across entities can be quantified by systemic risk measures, aimed at capturing tail comovements of firms' balance sheets, as well as the resulting negative spill-overs to the real economy. Adrian and Brunnermeier (2011) introduce CoVar, which relates the systemic risk contribution of an individual entity to the value of risk of the overall system, conditioned on the institution being in a distressed state. Acharaya, Engle, and Richardson (2012) propose the systemic expected shortfall index to measure the expected amount of undercapitalization of a bank under the occurrence of a systemic event making the overall financial system undercapitalized. A related systemic index, SRISK, is introduced by Brownless and Engle (2015) to measure ex ante the expected capital shortfall experienced by a firm under a prolonged period of market distress. Their index can be computed using the firm's size, leverage, and expected equity loss experienced when the market declines. An axiomatic foundation, which includes many statistical risk measures proposed in the literature as special cases, is given in Chen, Iyengar, and Moallemi (2013).

Ample empirical evidence suggests that financial institutions react to asset price changes by actively managing their balance sheets (see Adrian and Shin 2008, 2010; Greenlaw et al. 2008; among others). This may lead to forced sales of illiquid assets, which in turn depress prices and prompt financial distress at other banks that hold the same assets. Key contributions in this direction include Shleifer and Vishny $(1992,2011)$ and Brunnermeier and Pedersen (2009), who consider the theoretical underpinnings of this approach. Chen, Iyengar, and Moallemi (2014) analyze the role of common asset holdings in the propagation of shocks, and illustrate how portfolio rebalancing may depress asset prices.

Motivated by recent empirical evidence provided by Adrian and Shin (2010), showing that commercial banks actively track their leverage ratios, we develop a dynamic model to capture price dynamics arising when a portion of the market is constrained by such leverage targeting requirements. In this setting, leverage adjustments and fluctuations in asset returns reinforce each other via a feedback mechanism. A sudden drop in the market price of an asset forces a leverage targeting bank to sell even more units in order to meet its target leverage. If other potential buyers face similar constraints at the same time, the result is an amplification effect.

Some studies have also analyzed the speed at which banks adjust their leverage ratio. Berger et al. (2008) find strong evidence that poorly capitalized banks adjust toward their targets more quickly than well-capitalized banks. Gropp and Heider (2010) find that the speed adjustment of banks towards their target leverage is on the order of $45 \%$.

None of the above papers consider price linkages arising from the leverage targeting constraint. A notable exception is Greenwood, Landier, and Thesmar (2014), who provide and calibrate a model of fire-sale spillovers. Their study takes as given the asset holdings of financial institutions, liquidity of assets, and the price impact generated by liquidation procedures due to adverse shocks. Greenwood, Landier, and Thesmar (2014) provide formulas 
quantifying the aggregate vulnerability of the financial system as well as the contribution of each individual bank to vulnerability. Duarte and Eisenbach (2013) decompose this vulnerability measure into three key factors: size, leverage and illiquidity concentration. They provide an empirical analysis identifying periods during which each of these factors has the highest impact on fire-sales externalities.

Our study is related to Greenwood, Landier, and Thesmar (2014) and Duarte and Eisenbach (2013), but presents important differences, which we outline next. Our market is divided into two sectors, referred to as the banking sector and nonbanking sector, respectively. Firms in the banking sector actively manage their leverage ratios to conform with a prespecified target level. The nonbanking sector consists of institutions that do not actively target a fixed leverage, such as mutual funds, money market funds, insurances, and pension funds. These type of organizations are primarily equity funded and do not exhibit cyclicality of leverage behavior. In contrast to Greenwood, Landier, and Thesmar (2014) and Duarte and Eisenbach (2013), who focus on first-order effects of fire-sales externalities, we also take into account higher order effects caused by repeated rounds of deleveraging in response to a negative shock. Such higher order effects become substantial in certain regimes due to induced transmission and amplification mechanisms. Our main result shows that this happens when the size of leverage targeting banks grows too much relative to the elasticity-weighted size of the nonbanking sector. Under this regime, asset prices become highly sensitive to shocks and the system enters a state of high vulnerability.

We also make other contributions to the existing literature. We relate the price impact rule postulated by Greenwood, Landier, and Thesmar (2014) to the reciprocal of the elasticity-weighted size of the nonbanking sector, measured as the dollar amount held in the asset. Doubling the size of the nonbanking sector or its price elasticity reduces the price impact of the initial shocks by a factor of two. Second, in our model, asset holdings and prices follow dynamics forced by the leverage targeting requirement and market clearing conditions. In particular, we obtain that the demand curve of the leverage ratio trackers is upward sloping, which is consistent with the analysis of Adrian and Shin (2010) and Greenlaw et al. (2008).

The dynamic nature of our model allows quantifying spillover effects propagating to other asset classes due to multiple rounds of deleveraging. The liquidating firms may choose to sell other assets than the one originally experiencing a price decrease, thereby affecting firms with a similar balance sheet compositions.

Before proceeding further, we introduce notations and definitions used throughout the paper. For two vectors $u=\left(u_{1} \cdots u_{n}\right)^{\top}$ and $v=\left(v_{1} \cdots v_{n}\right)^{\top}$, we let $u \circ v=\left(u_{1} v_{1} \cdots u_{n} n_{n}\right)^{\top}$ denote the componentwise product, also known as the Hadamard product. Similarly, $\frac{u}{v}=$ $\left(u_{1} / v_{1} \cdots u_{n} / n_{n}\right)^{\top}$ denotes the component-wise ratio. $\operatorname{Diag}(u)$ is the diagonal 
matrix with $u$ on the diagonal. The vector of ones is denoted $\mathbf{1}$, where the dimension is clear from the context.

\section{Market Participants and Assets}

The market is divided into two sectors: the banking sector and the nonbanking sector. We think of the banking sector as consisting primarily of commercial banks and investment banks. Their distinguishing feature in our model is that they actively manage their leverage ratios to conform with a prespecified target level. This behavior has been documented empirically by Adrian and Shin (2010) using flows of funds data. Adrian and Shin (2014) use individual bank data to show that banks even exhibit procyclical leverage. Our assumption of constant leverage is thus conservative in this case, and our results understate the effect that would arise from procyclical leverage. Procyclicality of leverage driven by value at risk also has been microfounded in the study by Adrian and Shin (2014). Adrian and Boyarchenko (2013) present a macroeconomic model where intermediate borrowing is restricted by a value at risk constraint that gives rise to procyclical leverage.

The nonbanking sector consists of institutions that do not actively target a fixed leverage. This includes mutual funds, money market funds, insurances, and pension funds that do not exhibit cyclicality in their leverage behavior.

\subsection{The banking sector}

There are $N$ leverage targeting banks indexed by $i$. The state of each bank is described by its balance sheet, which consists of assets, equity, and debt. In our model, banks manage their capital structure exclusively by buying and selling assets, and by increasing or reducing their level of debt. They do not raise new equity capital in response to a positive or negative shock to the asset value. This is in line with empirical evidence reported by Adrian, Colla, and Shin (2012) showing that banks reduce debt during downturns, and do not issue equity even when asset values increase. Figures 3 and 4 in their paper show that equity of banks changes very little from one quarter to the next. In other words, bank lending expands when its leverage increases, while deleveraging is usually accompanied by a sharp contraction of lending.

There are $K$ types of assets available, indexed by $k$, whose market prices are denoted $P_{t}^{k}$. We write

$$
P_{t}=\left(P_{t}^{1} P_{t}^{2} \cdots P_{t}^{K}\right)^{\top}
$$

for the column vector of asset prices. The aggregate supply of each asset is fixed and given by $Q_{\text {tot }}=\left(Q_{\text {tot }}^{1} \cdots Q_{\text {tot }}^{K}\right)^{\top}$. The quantity (number of units) of asset $k$ held by bank $i$ is denoted $Q_{t}^{k i}$. For each bank, its vector of holdings is written as

$$
Q_{t}^{i}=\left(Q_{t}^{1 i} Q_{t}^{2 i} \cdots Q_{t}^{K i}\right)^{\top}
$$


The market value of the $i$ :th bank's holdings of asset $k$ is $A_{t}^{k i}=P_{t}^{k} Q_{t}^{k i}$. Similarly, as for the quantities, we write

$$
A_{t}^{i}=\left(A_{t}^{1 i} A_{t}^{2 i} \cdots A_{t}^{K i}\right)^{\top} .
$$

The total market value of the $i$ :th bank's assets is given by $1^{\top} A_{t}^{i}=\sum_{k=1}^{K} A_{t}^{k i}$.

To fund their operations, banks issue debt. We do not distinguish between different sources of debt financing (repo market, interbanking debt, and deposits) and use $D_{t}^{i}$ to denote the total amount of debt issued by bank $i$ at $t$. Throughout the rest of the paper, we assume that the interest rate $r$ on the debt is zero. This serves to simplify the theoretical analysis without having any qualitative impact on the results. For completeness, we provide all key formulas for the nonzero interest rate case in Appendix A.

The key assumption that drives our model is that each bank tracks a fixed leverage target, keeping the debt-to-equity ratio equal to a fixed value $\lambda_{i}$, which may be different for different banks. That is, we assume

$$
\frac{D_{t}^{i}}{1^{\top} A_{t}^{i}-D_{t}^{i}}=\lambda_{i}, \quad i=1, \ldots, N .
$$

The conclusions of our analysis will remain largely unchanged if $\lambda_{i}$ were allowed to vary somewhat over time; the critical assumption is that banks actively make an effort to stabilize their leverage.

Through its operations, each bank $i$ in the system generates a net operating income $\Delta R_{t}^{i}$ in the time interval $[t, t+\Delta t]$. This includes profits and losses derived from financial transactions, as well as payment and collection of interests on various transactions conducted as a normal part of its business operations. The revenue stream can be stochastic and time-varying. We consider a stylized description of commercial banking behavior. Banks use funds raised through debt issuance and operational gains to purchase a variety of assets. Those include securities such as Treasury, municipal and corporate bonds, mortgage-backed securities, and loans, such as commercial and industrial, real estate, consumer, and government loans. ${ }^{1}$ They also liquidate part of their current holdings when they face losses and need to repay their debt. ${ }^{2}$

A fraction $\alpha_{t}^{k i}$ of this cash flow is devoted to managing the holdings in asset $k$. These fractions may be time and state dependent. Since there is no other way the bank can use its cash flow, we always have $\sum_{k=1}^{K} \alpha_{t}^{k i}=1$. We write

$$
\alpha_{t}^{i}=\left(\alpha_{t}^{1 i} \cdots \alpha_{t}^{K i}\right)^{\top},
$$

1 Banks also earn income from off-balance sheet items, such as lines of credit, letters of credit, asset management on behalf of wealthy individuals, and derivatives to hedge against credit or interest rates risk. Although we do not allow banks to invest in these assets, our conclusions would qualitatively stay the same if we were to incorporate them into the model.

2 In the case of a nonzero interest rate, there are also cash flows from servicing existing debt in each period. See Appendix A for details. 
and refer to these numbers as the cash-flow allocation weights. One particular strategy that is studied by Greenwood, Landier, and Thesmar (2014) is a fixed relative exposure policy. This means that the fraction of total value allocated to each individual asset depends on its relative size. This is accomplished by the cash-flow allocation weights $\alpha_{t}^{k i}=A_{t}^{k i} /\left(1^{\top} A_{t}^{i}\right)$.

Taken together, the above yields the fundamental cash-flow equation:

$$
P_{t+\Delta t}^{k} \Delta Q_{t}^{k i}=\alpha_{t}^{k i}\left(\Delta R_{t}^{i}+\Delta D_{t}^{i}\right), \quad i=1, \ldots, N, \quad k=1, \ldots, K .
$$

The left side gives the amount bank $i$ invests in asset $k$ at time $t+\Delta t$. The right-hand side is the cash flow resulting from (i) and (ii) described above, multiplied by $\alpha_{t}^{k i}$. Combining the leverage equation (1.1) and the cash-flow equation (1.2) gives the banks' demand curves. The following result is a special case of Proposition 5.1.

Proposition 1.1 The $i$ :th bank's incremental demand for asset $k$ is given by

$$
\Delta Q_{t}^{k i}=\frac{\alpha_{t}^{k i}}{P_{t+\Delta t}^{k}}\left(\lambda_{i} Q_{t}^{i \top} \Delta P_{t}+\left(1+\lambda_{i}\right) \Delta R_{t}^{i}\right) .
$$

The leverage ratio $\lambda_{i}$ and cash-flow allocation weights $\alpha_{t}^{k i}$ are directly related to the price elasticities of bank $i$. Indeed, in the absence of revenue shocks, that is, $\Delta R_{t}^{i}=0$, and if the prices of all, except the $k:$ th asset, are unchanged, that is $\Delta P_{t}^{h}=0$ for $h \neq k$, then (1.3) becomes

$$
\frac{\Delta Q_{t}^{k i}}{Q_{t}^{k i}}=\lambda_{i} \alpha_{t}^{k i} \frac{\Delta P_{t}^{k}}{P_{t+\Delta t}^{k}} .
$$

Note that the elasticity is positive, provided $\alpha_{t}^{k i}$ is. The reason may be understood as follows: if from time $t$ to time $t+\Delta t$ the price of one unit of the $k$-th asset rises, the firm will have to increase its debt level to track the leverage ratio and invest the resulting amount by purchasing asset units. By a symmetric reasoning, if the price decreases, the firm will reduce its debt by selling asset units. This reflects the upward-sloping form of the demand curve caused by the leverage ratio-tracking behavior.

\subsection{The nonbanking sector}

The nonbank institutions also trade in the available assets. This gives rise to additional demand, which we refer to as the nonbanking demand, modeled in reduced form through exogenously specified demand curves. We assume that these demand curves are decoupled across assets in the sense that the nonbanking demand for asset $k$ only depends on the price of asset $k$, and not on the prices of the other assets. Modeling the nonbanking demand in this way allows us to focus on price fluctuations caused by balance sheet linkages among the leverage ratio-tracking banks. 
At time $t$, the nonbanking sector holds a quantity $Q_{t}^{k, \text { nb }}$ of asset $k$, and we write $A_{t}^{k, \mathrm{nb}}=P_{t}^{k} Q_{t}^{k, \mathrm{nb}}$ for the corresponding asset value. The incremental demand is given by

$$
\Delta Q_{t}^{k, \mathrm{nb}}=\frac{\gamma_{k}}{P_{t+\Delta t}^{k}} Q_{t}^{k, \mathrm{nb}}\left(\Delta Z_{t}^{k}-\Delta P_{t}^{k}\right)
$$

for asset-specific demand shocks $\Delta Z_{t}^{k}$ and positive constants $\gamma_{k}$. We write

$$
Q_{t}^{\mathrm{nb}}=\left(Q_{t}^{1, \mathrm{nb}} \cdots Q_{t}^{K, \mathrm{nb}}\right)^{\top}, \Delta Z_{t}=\left(\Delta Z_{t}^{1} \cdots \Delta Z_{t}^{K}\right)^{\top}, \gamma=\left(\gamma_{1} \cdots \gamma_{K}\right)^{\top} .
$$

The form (1.5) is justified by two features. First, if there were no leverage ratio trackers present, market clearing would force $\Delta Q_{t}^{k, \mathrm{nb}}=0$, leading to asset price dynamics $\Delta P_{t}^{k}=\Delta Z_{t}^{k}$. This gives an alternative interpretation of $\Delta Z_{t}^{k}$ as the equilibrium price increment in the absence of leverage ratio trackers. Second, the relationship between price and demand conditional on $\Delta Z_{t}^{k}=0$ is given by

$$
\frac{\Delta Q_{t}^{k, \mathrm{nb}}}{Q_{t}^{k, \mathrm{nb}}}=-\gamma_{k} \frac{\Delta P_{t}^{k}}{P_{t+\Delta t}^{k}},
$$

so that $\gamma_{k}$ can be interpreted as the elasticity of the nonbanking demand for asset $k$, comparable to $\lambda_{i} \alpha_{t}^{k i}$ in (1.4). Note that since $\gamma_{k}$ is positive, the nonbanking demand curve is downward sloping, unlike the demand curve of the leverage ratio-tracking banks. This is the behavior one expects from unconstrained agents. We let $\gamma=\left(\gamma_{1}, \ldots, \gamma_{k}\right)$ be the vector of price elasticities for assets held by the nonbanking sector.

Although different specifications of nonbanking demands could be considered, they would not have a significant impact on our results, as long as they are downward sloping.

\section{Asset Prices and Holdings}

In this section we derive the dynamics of asset prices and holdings enforced by market clearing. A key quantity in this regard is the systemicness matrix, introduced below. We also discuss the relation with linear price impact models, which leads to an outline of how our model could be calibrated.

\subsection{Market dynamics and the systemicness matrix}

The dynamics of asset prices, as well as the holdings of the banks and of the external market, are computed by imposing market clearing. The marketclearing condition is

$$
Q_{t}^{\mathrm{nb}}+\sum_{i=1}^{N} Q_{t}^{i}=Q_{\mathrm{tot}}
$$


where the vector $Q_{\text {tot }}$ of aggregate supplies is fixed through time. A key quantity in our analysis is the systemicness matrix $\boldsymbol{S}_{t}$ given by

$$
\boldsymbol{S}_{t}=\sum_{i=1}^{N} \frac{\alpha_{t}^{i}}{\gamma \circ A_{t}^{\mathrm{nb}}} \lambda_{i} A_{t}^{i \top},
$$

or, in component-wise form,

$$
S_{t}^{k \ell}=\sum_{i=1}^{N} \alpha_{t}^{k i} \frac{\lambda_{i} A_{t}^{\ell i}}{\gamma_{k} A_{t}^{k, \mathrm{nb}}} .
$$

The systemicness matrix is a key determinant for excess correlation induced by the leverage targeting banks. The analysis underlying this claim rests on the following result, which gives the dynamics of asset prices and holdings. It is a special case of Proposition 5.2.

Proposition 2.1 The cash-flow equation (1.2), the leverage equation (1.1), the external demand function (1.5), and the market-clearing condition (2.1) imply that the dynamics of asset prices and asset holdings are given by

$$
\begin{aligned}
\frac{\Delta P_{t}}{P_{t}} & =\left(\boldsymbol{I}-\boldsymbol{S}_{t}\right)^{-1}\left[\frac{\Delta Z_{t}}{P_{t}}+\sum_{i=1}^{N} \frac{\alpha_{t}^{i}}{\gamma \circ A_{t}^{\mathrm{nb}}}\left(1+\lambda_{i}\right) \Delta R_{t}^{i}\right], \\
\Delta A_{t}^{i} & =Q_{t}^{i} \circ \Delta P_{t}+\alpha_{t}^{i}\left(\lambda_{i} Q_{t}^{i \top} \Delta P_{t}+\left(1+\lambda_{i}\right) \Delta R_{t}^{i}\right), \\
\Delta A_{t}^{\mathrm{nb}} & =Q_{t}^{\mathrm{nb}} \circ\left(\gamma \circ \Delta Z_{t}-(\gamma-\mathbf{1}) \circ \Delta P_{t}\right),
\end{aligned}
$$

assuming that the matrix inverse exists. ${ }^{3}$

Let us analyze the expression (2.3) for the vector of asset price returns. The quantity in square brackets can be thought of as a vector of initial aggregate return shocks. Through the influence of the systemicness matrix $\boldsymbol{S}_{t}$, these shocks are then amplified and propagated across asset classes, potentially leading to significant excess correlation in the realized asset returns. To develop a more detailed understanding for this mechanism, suppose all eigenvalues of $\boldsymbol{S}_{t}$ have modulus strictly less than one. Then the inverse $\left(\boldsymbol{I}-\boldsymbol{S}_{t}\right)^{-1}$ can be expanded as a power series, resulting in

$$
\frac{\Delta P_{t}}{P_{t}}=\left[\boldsymbol{I}+\boldsymbol{S}_{t}+\boldsymbol{S}_{t}^{2}+\boldsymbol{S}_{t}^{3}+\ldots\right] \Delta Y_{t},
$$

${ }^{3}$ Recall our convention for componentwise division of vectors: $\Delta P_{t} / P_{t}=\left(\Delta P_{t}^{1} / P_{t}^{1}, \ldots, \Delta P_{t}^{K} / P_{t}^{K}\right)$. 
where $\Delta Y_{t}$ is the vector of initial aggregate returns,

$$
\Delta Y_{t}=\frac{\Delta Z_{t}}{P_{t}}+\sum_{i=1}^{N} \frac{\alpha_{t}^{i}}{\gamma \circ A_{t}^{\mathrm{nb}}}\left(1+\lambda_{i}\right) \Delta R_{t}^{i}
$$

Equation (2.4) clarifies how the initial return shock $\Delta Y_{t}$ is translated into realized returns. First, there is a direct impact, corresponding to the first term $\boldsymbol{I}$ in the power series expansion. Second, there is an indirect effect arising from a first round of deleveraging by the banks (in the case of negative shocks), corresponding to the term $\boldsymbol{S}_{t}$. The term $\boldsymbol{S}_{t}^{2}$ corresponds to a second round of deleveraging, and so on. Each round has an impact on the price, and the total realized return is the aggregate outcome of this process.

The contribution to realized asset returns arising from the presence of leverage targeting banks can be interpreted as a measure of fire-sale externalities, captured by the term $\boldsymbol{S}_{t}+\boldsymbol{S}_{t}^{2}+\boldsymbol{S}_{t}^{3}+\ldots$ Indeed, for simplicity, we assume zero revenue shocks, $\Delta R_{t}^{i}=0$, and have

(Return with banks $)_{t}-(\text { Return without banks })_{t}=\left(\boldsymbol{I}-\boldsymbol{S}_{t}\right)^{-1} \frac{\Delta Z_{t}}{P_{t}}-\frac{\Delta Z_{t}}{P_{t}}$

$$
=\left[\boldsymbol{S}_{t}+\boldsymbol{S}_{t}^{2}+\boldsymbol{S}_{t}^{3}+\ldots\right] \frac{\Delta Z_{t}}{P_{t}},
$$

using the power series expansion in (2.4) for the second equality. Thus, the difference in returns arises from the repeated price impact caused by the leverage-targeting behavior of the banking sector. Omitting higher powers of $\boldsymbol{S}_{t}$ would result in a similar notion of externalities as the aggregate vulnerability measure proposed by Greenwood, Landier, and Thesmar (2014) and analyzed empirically by Duarte and Eisenbach (2013). However, as we discuss in detail in Section 3, the higher order terms become significant in certain regimes associated with excessive growth of the banking sector relative to the nonbanking sector. In such regimes the linearized measure, where only the first term is retained, may substantially understate potential externalities from fire sales.

\subsection{Relation with linear price impact models}

A simple way to model price impact is by linear scaling: buying a dollar amount $x_{k}$ of an asset $k$ generates a return impact $\eta_{k} x_{k}$, where $\eta_{k}>0$ is an asset-specific price impact ratio expressed as units of returns per dollar of net purchase. This model has been used by Ellul, Jotikasthira, and Lundblad (2011) (see also Coval and Stafford (2007); Jotikasthira, Lundblad, and Ramadorai (2012)). In Greenwood, Landier, and Thesmar (2014), it is used for studying price contagion caused by balance sheet linkages, and it is therefore of interest to compare this reduced-form model of price impact with the expression (2.4), which links an initial return shock to actual realized returns. 
Most of the analysis in Greenwood, Landier, and Thesmar (2014) assumes that banks, in addition to tracking fixed leverage ratios, maintain constant relative exposures. That is, the fraction $A_{t}^{k i} /\left(\boldsymbol{1}^{\top} A_{t}^{i}\right)$ of the total asset value held in asset $k$ is kept at a constant level $M_{k i}$. Combining this with the linear price impact model described above, they derive the vector of return impacts,

$$
\left(\boldsymbol{H} \boldsymbol{M}^{\top} \operatorname{Diag}\left(\lambda \circ A_{t}^{\text {tot }}\right) \boldsymbol{M}\right) \Delta Y_{t},
$$

caused by one round of deleveraging in response to an initial shock $\Delta Y_{t}$. Here, $\boldsymbol{H}=\operatorname{Diag}\left(\eta_{1}, \ldots, \eta_{k}\right)$ is the diagonal matrix with the price impact ratios on the diagonal, and $A_{t}^{\text {tot }}=\left(1^{\top} A_{t}^{1}, \ldots, 1^{\top} A_{t}^{n}\right)$ is the vector containing the total asset value of each bank. Comparing (2.5) with (2.4), we see that we should have

$$
\boldsymbol{S}_{t}=\boldsymbol{H} \boldsymbol{M} \operatorname{Diag}\left(\lambda \circ A_{t}^{\mathrm{tot}}\right) \boldsymbol{M}^{\top} .
$$

Equation (2.6) establishes a direct relation between our systemicness matrix $\boldsymbol{S}$ and the individual components defining the aggregate vulnerability measure in Greenwood, Landier, and Thesmar (2014) and Duarte and Eisenbach (2013). Furthermore, the assumption of constant relative exposures means we can impose $\alpha_{t}^{k i}=M_{k i}=A_{t}^{k i} /\left(\boldsymbol{I}^{\top} A_{t}^{i}\right)$. Component-wise comparison of the left- and right-hand sides of (2.6) then gives the equality

$$
\eta_{k}=\frac{1}{\gamma_{k} A_{t}^{k, \mathrm{nb}}} .
$$

The $k$ :th price impact ratio $\eta_{k}$ can thus be interpreted as one over the elasticity-weighted size of the external market, measured as the dollar amount held in asset $k$. In particular, doubling the size of the external market reduces the price impact of initial shocks by a factor two; doubling the elasticity of the external market has the same effect.

\subsection{Toward model calibration}

We discuss procedures and data that can guide the calibration of our model. First, we identify categories of assets held on the balance sheet of banks that are potentially subject to fire sales. These include sovereign and corporate bonds, commercial real estate, and mortgages. One can then estimate banks' exposures to the different asset categories using data compiled from regulatory authorities. For instance, quarterly released data for U.S. commercial banks can be used to construct a time series of banks' exposures to different asset classes. The total asset value of each bank is obtained by summing its exposures to the different asset classes. From this, we compute the fraction of bank $i$ 's exposure to asset class $k$, and consequently estimate the allocation strategies $\alpha^{k i}$. Such a methodology is also followed by Duarte and Eisenbach (2013), who group assets 
into thirteen categories so as to calibrate the matrix of portfolio weights without having cross-asset price impacts of fire-sales.

Next, we calibrate the debt-to-equity ratio. The debt estimate $D^{i}$ can be obtained by subtracting the equity value of bank $i$ from the asset value $A^{i}$. We would then need to estimate the total size of the nonbanking sector on each asset class. As for the banking sector, this can be done using data released by regulators. For instance, the European Commission publishes assessment reports giving balance sheet decompositions of the nonbanking sector along with their evolution over time (see, for instance, Table 3 in European Commission (2012)).

Finally, we need to estimate the elasticity parameter $\gamma_{k}$. For this, we can use the equation (2.7) and imply reasonable values for $\gamma_{k} A_{t}^{k, \text { nb }}$ from studies estimating the price impact ratios $\eta_{k}$. Greenwood, Landier, and Thesmar (2014) and Duarte and Eisenbach (2013) use an across-the-board value of $\eta_{k}=10^{-13}$ for all assets. In view of Equation (2.7), this is likely too small for many asset classes of interest. For example, Ellul, Jotikasthira, and Lundblad (2011) find a value of the order $\eta_{k}=1.3 \times 10^{-8}$ in 2001 for high-yield bonds (see Table 8 in their paper), although there is variation over time. ${ }^{4}$ This translates into $\gamma_{k} A_{t}^{k, \mathrm{nb}}=7.8 \times 10^{7}$, which is very small in comparison to the values used by Greenwood, Landier, and Thesmar (2014). Of course, one would expect significant variation across different asset classes.

\section{Systemic Impact of Leverage Targeting Banks}

In this section we discuss how the presence of leverage targeting banks affects asset returns. This is captured by the systemicness matrix $\boldsymbol{S}_{t}$, as is most conveniently seen from the expression (2.4). We first establish bounds on the spectral radius of $\boldsymbol{S}_{t}$, which is the main determinant for the rate of convergence of the power series in (2.4). Using these bounds we study how different cash-flow allocation strategies affect the sensitivity of asset returns to shocks. The systemicness matrix may be interpreted as the matrix of edge weights in a weighted network whose nodes are the available assets. This interpretation provides a way of studying excess correlation induced by banks' deleveraging activity, as well as quantifying the contribution of individual banks to aggregate systemic risk.

\subsection{The spectral radius of the systemicness matrix}

The main determinant for the rate of convergence of the power series in (2.4), and consequently for the size of the realized return $\Delta P_{t} / P_{t}$ above and beyond $\Delta Y_{t}$, is the spectral radius $\rho\left(\boldsymbol{S}_{t}\right)$, given as the maximum eigenvalue modulus of $\boldsymbol{S}_{t}$. The spectral radius can be thought of as an aggregate level of

\footnotetext{
${ }^{4}$ For the years 2001-2005, Ellul, Jotikasthira, and Lundblad (2011) find price impact ratios of $1.3 \times 10^{-8}, 1.1 \times 10^{-8}, 6.2 \times 10^{-9}, 6.4 \times 10^{-9}$, and $9 \times 10^{-10}$ for high-yield bonds.
} 
vulnerability in the system, thus playing a similar role as the aggregate vulnerability index introduced by Greenwood, Landier, and Thesmar (2014). However, in our case systemicness crucially depends on the relation between the banking and nonbanking sectors.

Notice that the spectral radius is homogeneous in the sense that $\rho\left(c \boldsymbol{S}_{t}\right)=$ $c \rho\left(\boldsymbol{S}_{t}\right)$ for any constant $c>0 .{ }^{5}$ From the definition of the systemicness matrix in (2.2), it then follows that scaling up the leverage ratios or the banks' asset sizes by some factor increases the spectral radius by that factor. In contrast, scaling up the elasticity weighted size of the nonbanking sector by some factor brings the spectral radius down by the same factor.

The following result gives some simple bounds on the spectral radius, and these are useful in analyzing the effect of various model parameters on price sensitivity.

Proposition 3.1 Assume all asset holdings and all cash-flow allocation weights $\alpha_{t}^{k i}$ are nonnegative, and let $\rho\left(\boldsymbol{S}_{t}\right)$ be the spectral radius of $\boldsymbol{S}_{t}$. We then have the bounds

$$
\max _{k=1, \ldots, K} \frac{\sum_{i=1}^{N} \lambda_{i} \alpha_{t}^{k i} A_{t}^{k i}}{\gamma_{k} A_{t}^{k, \mathrm{nb}}} \leq \rho\left(\boldsymbol{S}_{t}\right) \leq \max _{k=1, \ldots, K} \frac{\sum_{i=1}^{N} \lambda_{i} \alpha_{t}^{k i} 1^{\top} A_{t}^{i}}{\gamma_{k} A_{t}^{k, \mathrm{nb}}} .
$$

Consider first the upper bound. Recalling the interpretation (1.4) of $\lambda_{i} \alpha_{t}^{k i}$ as a demand elasticity, the upper bound is a measure of the size of the leverage-targeting banks relative to the size of the nonbanking sector, as measured by elasticity-weighted assets. When the nonbanking sector is large, then $\rho\left(\boldsymbol{S}_{t}\right)$ is small, leading to a moderate impact on realized returns by (2.4).

Consider now the lower bound. Again, this is a ratio between elasticityweighted assets; however, the numerator now only involves the banks' holdings of the $k$ :th asset (for each fixed $k$ ), as opposed to total asset holdings. Symmetrically to the previous case, if the nonbanking sector is small in relative terms, then $\rho\left(\boldsymbol{S}_{t}\right)$ is large (close to one), causing a strong impact on realized returns. An even more extreme situation occurs if there exists an asset $k$ such that

$$
\sum_{i=1}^{N} \lambda_{i} \alpha_{t}^{k i} A_{t}^{k i}>\gamma_{k} A_{t}^{k, \mathrm{nb}}
$$

because then $\rho\left(\boldsymbol{S}_{t}\right)>1$ and the infinite sum in (2.4) does not converge. Indeed, $\operatorname{det}\left(c \rho\left(\boldsymbol{S}_{t}\right) \boldsymbol{I}-c \boldsymbol{S}_{t}\right)=c^{K} \operatorname{det}\left(\rho\left(\boldsymbol{S}_{t}\right) \boldsymbol{I}-\boldsymbol{S}_{t}\right)=0$, whence $c \rho\left(\boldsymbol{S}_{t}\right)$ is an eigenvalue of $c \boldsymbol{S}_{t}$. This eigenvalue is
maximal, since otherwise, by the same token, $\boldsymbol{S}_{t}$ would have an eigenvalue larger than $\rho\left(\boldsymbol{S}_{t}\right)$. 
The above analysis indicates that externalities are more severe when assets are concentrated on balance sheets of large and highly levered banks. This is consistent with the results in Duarte and Eisenbach (2013), where size is identified as a key driver of the increase in aggregate vulnerability before the financial crisis. Our results also support the findings of Acharaya et al. (2010), who relate systemic risk to the size of financial institutions, and suggest a tax mechanism based on size to make them internalize their externalities.

\subsection{Cash-flow allocation strategies and sensitivity of returns}

The bounds in Proposition 3.1 depend on the banks' cash-flow allocation weights $\alpha_{t}^{k i}$. It is therefore natural to ask how the allocation decisions of individual banks influence the overall sensitivity of realized returns to shocks. As in Greenwood, Landier, and Thesmar (2014), we first consider the special case in which all banks use the fixed relative exposure strategy $\alpha_{t}^{k i}=A_{t}^{k i} /\left(1^{\top} A_{t}^{i}\right)$. The upper bound on the spectral radius becomes

$$
\rho\left(\boldsymbol{S}_{t}\right) \leq \max _{k=1, \ldots, K} \frac{\sum_{i=1}^{N} \lambda_{i} A_{t}^{k i}}{\gamma_{k} A_{t}^{k, \mathrm{nb}}} .
$$

When it is tight, this bound indicates that the system is less stable if there exists an asset class for which the holdings of highly levered banks are large relative to the elasticity weighted size of the nonbanking sector. This can be understood as follows. Under this allocation policy, if an asset class experiences high growth, banks will distribute higher fractions of their aggregate cash flow to it. If holdings of the nonbanking sector in this asset class are small, or asset demand elasticity low, the occurrence of a negative shock may induce sales volumes that are too large to be absorbed by the nonbanking sector. When this happens, the downward price pressure can destabilize the overall system.

This result also can be interpreted in the context of illiquidity concentration, identified by Duarte and Eisenbach (2013) as a key driver of aggregate vulnerability. Duarte and Eisenbach (2013) estimate it to be large when an asset class is illiquid and concentrated on balance sheets of highly levered banks. Our analysis indicates that illiquidity concentration exacerbates systemicness, in that a large right-hand side in (3.1) is likely to be indicative of a less stable system.

Next, we consider an allocation strategy consisting in selling (buying) the most liquid assets when there is a need to delever (lever up). Our proxy for the liquidity state of asset $k$ is the elasticity-weighted size of the nonbanking sector, $\gamma_{k} A_{t}^{k, \mathrm{nb}}$. Assuming that these quantities are either known 
or can be estimated by the banks, a liquidity-based strategy for cash-flow allocation is

$$
\alpha_{t}^{k i}=\frac{\gamma_{k} A_{t}^{k, \mathrm{nb}}}{\sum_{\ell=1}^{K} \gamma_{\ell} A_{t}^{\ell, \mathrm{nb}}} .
$$

It is shown in Section 2.2 that this can be interpreted as $\alpha_{t}^{k i}=\eta_{k}^{-1}\left[\eta_{1}^{-1}+\cdots+\eta_{K}^{-1}\right]^{-1}$, where the $\eta_{\ell}$ 's are price impact ratios in a linear model for price impact (see Equation (2.7)). An analogous liquidation strategy is considered by Greenwood, Landier, and Thesmar (2014), and liquidity is obtained by varying the price impact ratio across the different assets. Under the liquidity-based strategy, the spectral radius becomes equal to its upper bound, namely,

$$
\rho\left(\boldsymbol{S}_{t}\right)=\frac{\sum_{i=1}^{N} \lambda_{i} 1^{\top} A_{t}^{i}}{\sum_{k=1}^{K} \gamma_{k} A_{t}^{k, \mathrm{nb}}},
$$

see Appendix A for a proof. Here, the spectral radius only depends on the relative aggregate size of the banking and the nonbanking sectors. In particular, the existence of an asset class for which price elasticity is high and for which the nonbanking sector is large relative to the banking sector, would be enough to stabilize the system. The result may be understood as follows: if all banks adopt a liquidation procedure that focuses on an asset with very elastic nonbanking demand, then even severe deleveraging needs can be absorbed by the nonbanking sector. The remaining, potentially illiquid, assets will be unaffected since they are not subjected to fire sales.

Furthermore, the following proposition shows that the liquidity-based strategy, if adopted by a majority of banks, would lead to a more stable system. The proof is in Appendix A.

Proposition 3.2 Assume all asset holdings are nonnegative. Then the righthand side of (3.3) is smaller than the right-hand side of (3.1).

The above result is in agreement with the simulation study of Greenwood, Landier, and Thesmar (2014), who find that the aggregate vulnerability of banks under the liquidity-based strategy is much lower than under the relative exposure strategy.

In reality, banks' behavior is unlikely to be fully captured by either the fixed relative exposure strategy or the liquidity-based strategy. Rather, one would 
expect some intermediate strategy. Indeed, while focusing on the most liquid assets makes sense, banks may be constrained from doing so in practice. For example, if the most liquid asset is one that the bank does not currently hold, it cannot be sold for deleveraging purposes unless short-selling is possible. Moreover, and perhaps more importantly, the bank may want to get rid of "bad" assets if it anticipates further loss of value in the future, even if it means accepting losses today. Nonetheless, to the extent that banks do use the most liquid assets currently on their balance sheets, the above results indicate that this is desirable also from a systemic point of view.

\subsection{The network of asset prices}

The systemicness matrix has a natural interpretation as the weighted adjacency matrix of a network with $K$ nodes, corresponding to the available assets. This network has a directed edge from node $\ell$ to node $k$ with weight $S_{t}^{k \ell}$. The interpretation is straightforward: a return shock to asset $\ell$ of size $y_{\ell}$ propagates along the edge $(\ell, k)$ and results in a shock to asset $k$ of size $y_{k}=S_{t}^{k \ell} y_{\ell}$, due to banks adjusting their leverage. The shock $y_{k}$ forces further leverage adjustments, causing return shocks to other assets, and so on. The total realized return is the aggregate outcome of this process.

The expression (2.2) immediately lets us read off how the deleveraging activities of bank $i$ contribute to the overall one-step propagation of shocks from asset $\ell$ to asset $k$. The contribution is given by

$$
\alpha_{t}^{k i} \frac{\lambda_{i} A_{t}^{\ell i}}{\gamma_{k} A_{t}^{k, \mathrm{nb}}} .
$$

Summing over $k$ and $\ell$ gives the total one-step return impact caused by bank $i$,

$$
\lambda_{i} 1^{\top} A_{t}^{i} \sum_{k=1}^{K} \alpha_{t}^{k i} \frac{1}{\gamma_{k} A_{t}^{k, \mathrm{nb}}} .
$$

This quantity is (1) proportional to the leverage ratio $\lambda_{i},(2)$ proportional to total assets $1^{\top} A_{t}^{i}$, and (3) proportional to a weighted average of $1 /\left(\gamma_{k} A_{t}^{k, \mathrm{nb}}\right)$, which proxies for asset liquidity (see Section 2.2). The weights are the bank's cash-flow allocation weights. In other words, the strongest one-step systemic impact is exerted by large banks that are highly levered and allocate their cash flows to illiquid assets (i.e., assets with low and inelastic nonbanking demand.)

However, one-step return impacts give an incomplete view of the systemic properties of the banking sector as a whole, as well as the role of individual banks. The aggregate impact on the return of asset $k$ due to a shock in asset $\ell$ is given by the $(k, \ell)$ entry of the matrix

$$
\left(\boldsymbol{I}-\boldsymbol{S}_{t}\right)^{-1}=\boldsymbol{I}+\boldsymbol{S}_{t}+\boldsymbol{S}_{t}^{2}+\cdots,
$$


provided $\rho\left(\boldsymbol{S}_{t}\right)<1$. To see why neglecting higher order effects beyond the one-step impact may be misleading, consider the following example with three assets $(K=3)$ and two banks $(N=2)$. Suppose both banks track the same debt-over-equity leverage ratio $\lambda=9$ and have current assets and fixed relative exposure strategies given by

$$
A_{t}^{1}=\left[\begin{array}{l}
1 \\
9 \\
0
\end{array}\right], \alpha_{t}^{1}=\left[\begin{array}{c}
0.1 \\
0.9 \\
0
\end{array}\right], A_{t}^{2}=\left[\begin{array}{l}
0 \\
1 \\
4
\end{array}\right], \alpha_{t}^{2}=\left[\begin{array}{c}
0 \\
0.2 \\
0.8
\end{array}\right] .
$$

Letting the nonbanking sector elasticities and holdings satisfy $\gamma_{1} A_{t}^{1, \mathrm{nb}}=900, \gamma_{2} A_{t}^{2, \mathrm{nb}}=400$, and $\gamma_{2} A_{t}^{2, \mathrm{nb}}=300$, the systemicness matrix becomes

$$
\boldsymbol{S}_{t}=\left[\begin{array}{lll}
0.001 & 0.009 & 0 \\
0.02 & 0.187 & 0.018 \\
0 & 0.24 & 0.96
\end{array}\right],
$$

and its spectral radius is $\rho\left(\boldsymbol{S}_{t}\right)=0.97$, that is very close to one. Now, even though $\boldsymbol{S}_{t}^{3,1}=0$, the $(3,1)$ entry of $\left(\boldsymbol{I}-\boldsymbol{S}_{t}\right)^{-1}$ is 0.17 . This means that a shock to asset 1 has a sizable impact on the return of asset 3, even though the onestep effect is zero. In this example, there are two mechanisms that interact to create this phenomenon. First, transmission occurs: the balance sheet of bank 1 is such that the initial shock to asset 1 propagates and generates a shock on asset 2 . Second, amplification occurs: this induced shock is greatly amplified through the deleveraging activities of bank 2, causing a shock on asset 3 .

Here, the amplification is caused by the strong emphasis of bank 2 on asset 3 in combination with the poor liquidity status of that asset. Indeed, suppose bank 2 were to change its cash-flow allocation strategy to

$$
\alpha_{t}^{2}=\left[\begin{array}{c}
0 \\
0.8 \\
0.2
\end{array}\right],
$$

shifting emphasis toward the (somewhat) more liquid asset 2. This would have a dramatic impact on shock propagation: we now have $\rho\left(\boldsymbol{S}_{t}\right)=0.29$, and the $(3,1)$ entry of $\left(\boldsymbol{I}-\boldsymbol{S}_{t}\right)^{-1}$ becomes 0.002 .

This discussion serves to highlight two main messages. First, while the onestep effect of balance sheet linkages on asset returns tend to dominate, second and higher order effects may play an important role and should not be neglected. Second, it reinforces the conclusion of Proposition 3.2 and the subsequent discussion by illustrating the ameliorating influence of liquidity-based cash-flow allocation strategies. 


\section{Policy Implications}

Section 4.1 develops a simulation study to analyze the relation between instability and sector sizes, along with its dependence on banks' allocation strategies. We discuss policy suggestions aiming at promoting systemic stability in Section 4.2 .

\subsection{Asset growth and the extreme sensitivity regime}

We evolve the dynamical system to illustrate the relationship between the onset of instability and the growth of the banking sector relative to the nonbanking sector. Note that this is for illustrative purposes only and should not be thought of as a calibration exercise. In particular, parameter values are chosen in an ad hoc manner to exemplify typical qualitative behavior of the model.

The revenue shocks $\Delta R_{t}^{i}, i \in\{1, \ldots, N\}$ are chosen to be independent zero-mean Gaussian random variables with standard deviation 0.1 . Similarly, the asset-specific demand shocks $\Delta Z_{t}^{k}, k \in\{1, \ldots, K\}$, are independent zero mean Gaussian, uncorrelated with $\Delta R_{t}$, and with standard deviation 0.11 . The initial aggregate size of the banking sector is $8 \%$ of the aggregate size of the nonbanking sector. We set $N=K=2$ and the initial prices of both assets to $P_{0}^{1}=P_{0}^{2}=1$. The leverage ratios are taken to be $\lambda_{1}=\lambda_{2}=10$, and the demand elasticities are chosen to be $\gamma_{1}=\gamma_{2}=9$.

Figure 1 reports a stable realization of the system under the fixed relative exposure strategy. The spectral radius of the systemicness matrix stays bounded away from one, and correspondingly the total holdings of the banking sector in each asset class are much smaller than the holdings of the nonbanking sector. This is in line with the theoretical analysis of the lower and upper bounds of the spectral radius done in Section 3.1. Moreover, since the system is stable, we expect shocks to have a moderate impact on asset prices. This is confirmed by Figure 2 .

Next, we display a different realization of revenue shocks and asset-specific demand shocks, under which the same fixed relative exposure strategy as before leads to instability. This is shown in Figure 3. The banking sector grows significantly in asset 2 and even exceeds the nonbanking sector. When this happens the spectral radius gets extremely close to one, and puts the system in a regime of excessive correlation as detailed in Section 3.1. This is reflected in the bottom panel of Figure 4, which demonstrates a high sensitivity of the price of asset 2 to shocks when the system enters the high sensitivity regime. In contrast, for the same realization of the shocks, if banks adopt the liquidity-based allocation strategy (3.2) rather than the fixed relative exposure strategy. In this case the spectral radius stays well below one, and the nonbanking sector remains sufficiently large compared to the banking sector. Furthermore, the top panel of Figure 4 shows that the return spike that appeared under the fixed relative exposure strategy is no 

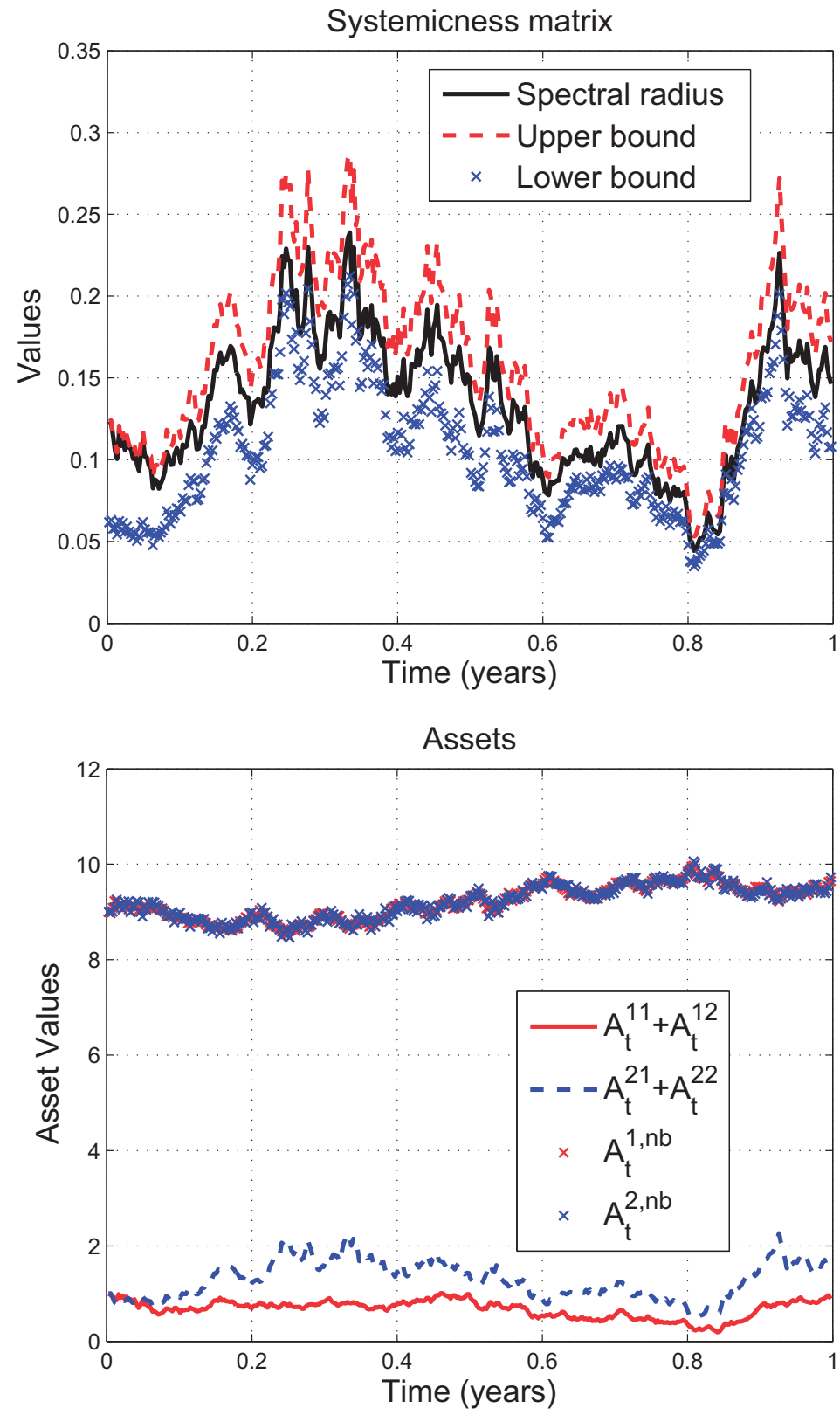

Figure 1

Stable realization

Top panel: Spectral radius of the systemicness matrix, including upper and lower bounds. Bottom panel: Total asset values. The banks follow the fixed relative exposure strategy. 


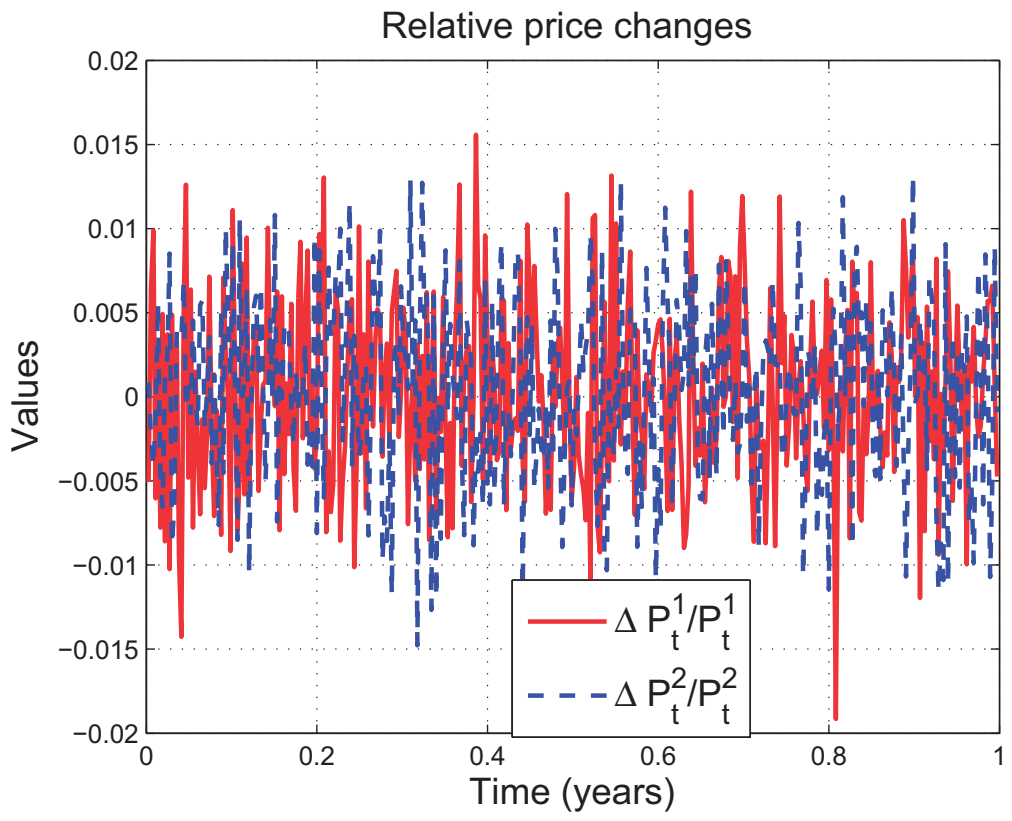

Figure 2

Relative price changes for the two assets under the same realization of shocks as in Figure 1

longer present. These results support the analysis in Section 3.2, where liquidity-based strategies are shown to lead to more stable systems.

This numerical example illustrates that instability and excess correlation may occur for some realizations of the system, but not for others, even when the underlying parameters are left unchanged. However, the likelihood of entering the unstable regime depends on the allocation strategy adopted by the banks. In particular, the liquidity-based strategy reduces the probability that this occurs.

\subsection{Informing policy making}

Our model suggests that the spectral radius of the systemicness matrix is an important determinant of price dynamics in the presence of leverage targeting banks. A large (close to one) spectral radius may lead to high sensitivity of prices to shocks, potentially triggering fire sales. What can a regulator do to mitigate these effects? The upper bound in (3.1) indicates that stability improves if (1) the banking sector is small, (2) the nonbanking sector is large, (3) nonbanking demand is highly elastic, (4) target leverage is low, or (5) banks assign low allocation weights to illiquid assets.

Clearly a regulator has limited ability to influence (1)-(3), and in any case, it is questionable whether preventive policies aimed at controlling the relative growth of the banking versus nonbanking sector would be desirable. One may argue that (4) could be achieved by imposing more stringent leverage ratio 
(a)

Systemicness matrix

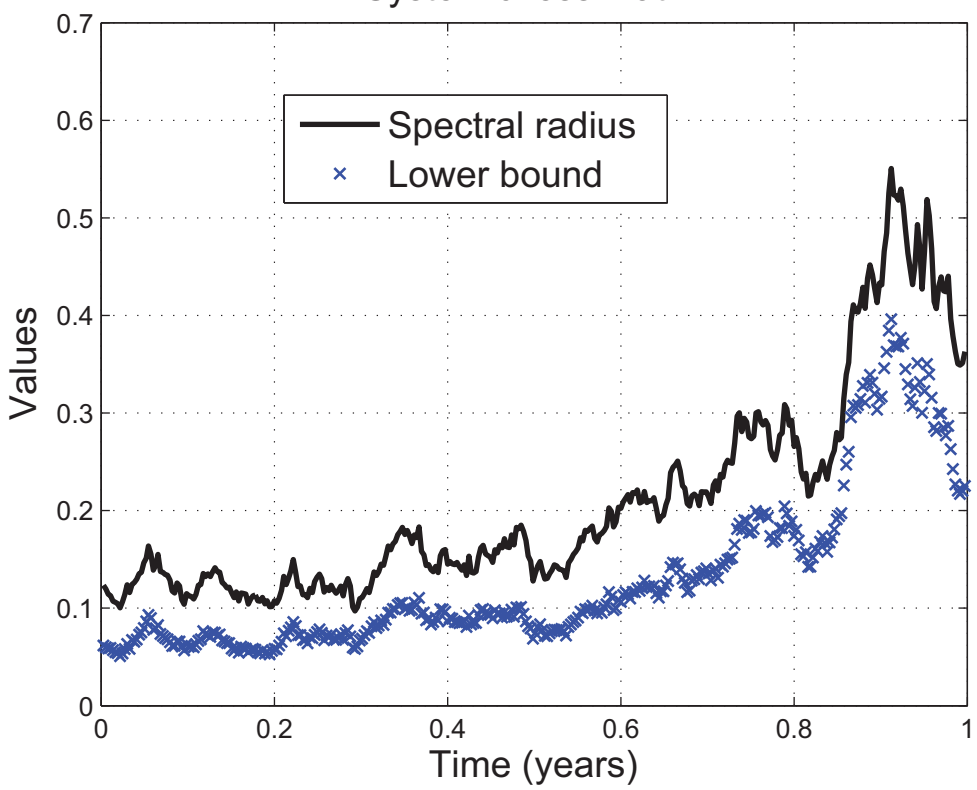

Systemicness matrix

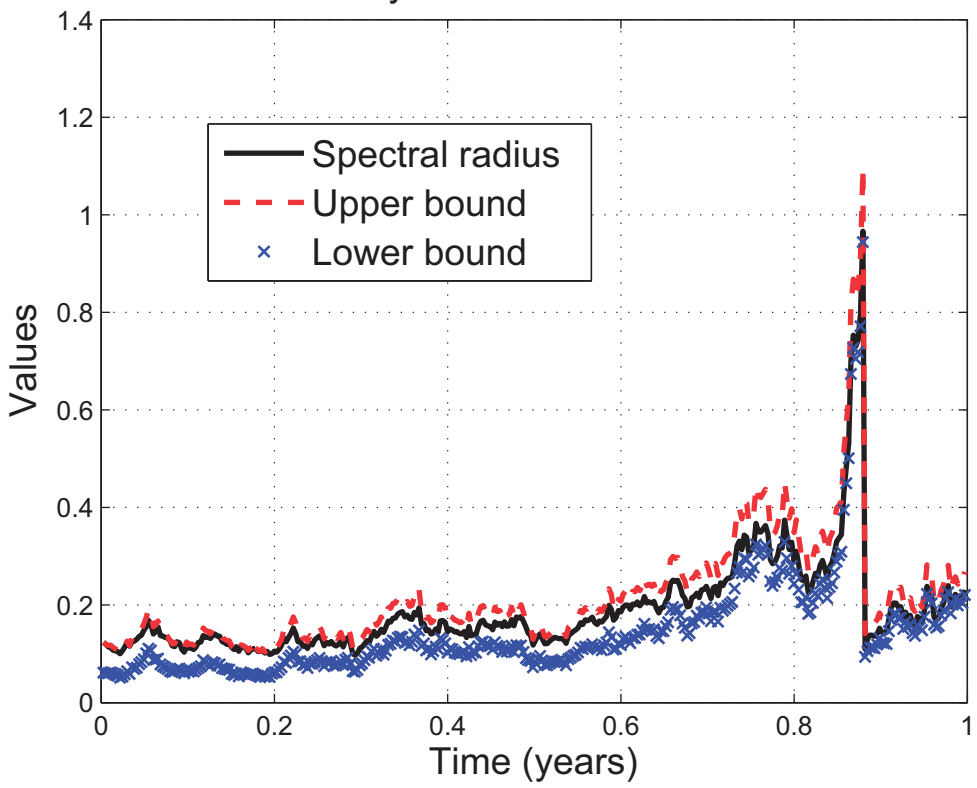

Figure 3

Unstable realization

(a) Spectral Radius of the systemicness matrix. Top panel: liquidity-based allocation strategy. Bottom panel: fixed relative exposure strategy. (b) Asset values. Top panel: liquidity-based allocation strategy. Bottom panel: fixed relative exposure strategy. All panels are generated under the same realization of shocks. 


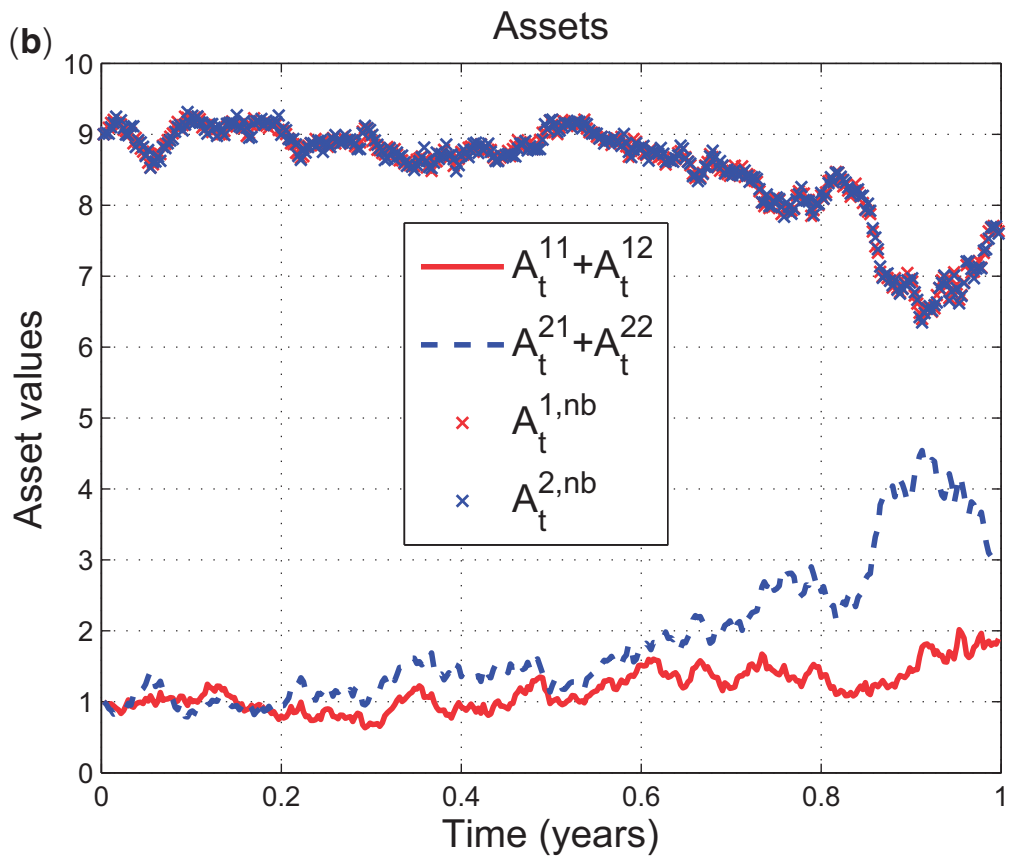

Assets

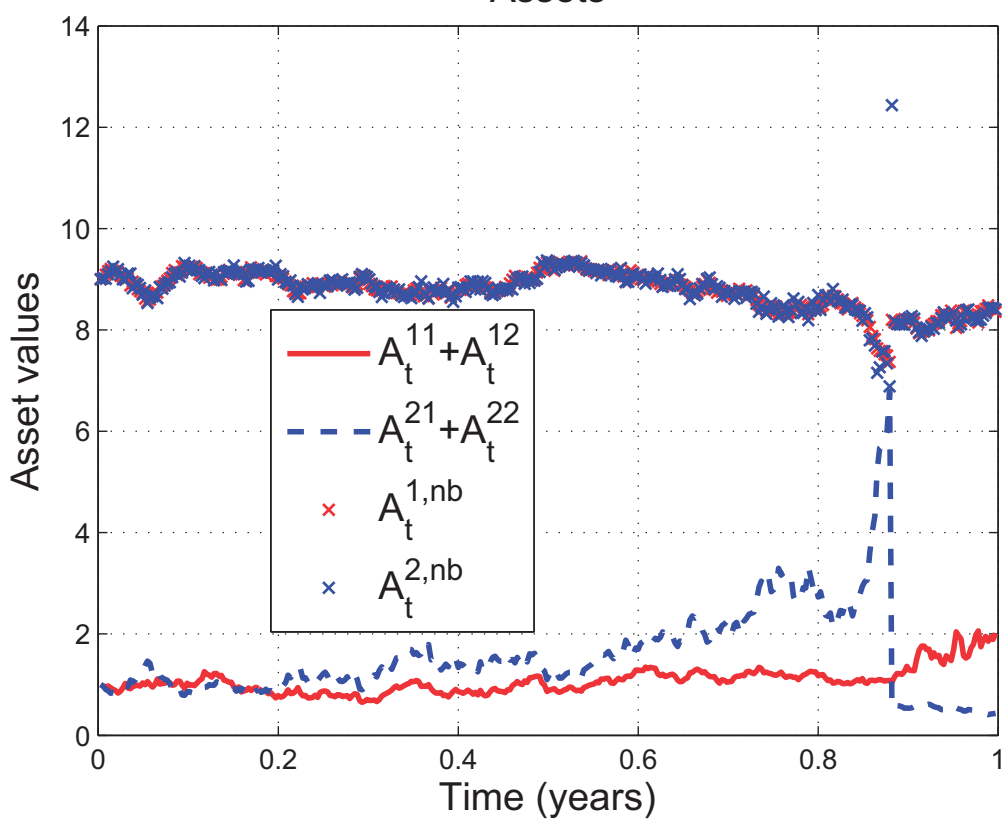

Figure 3

Continued 

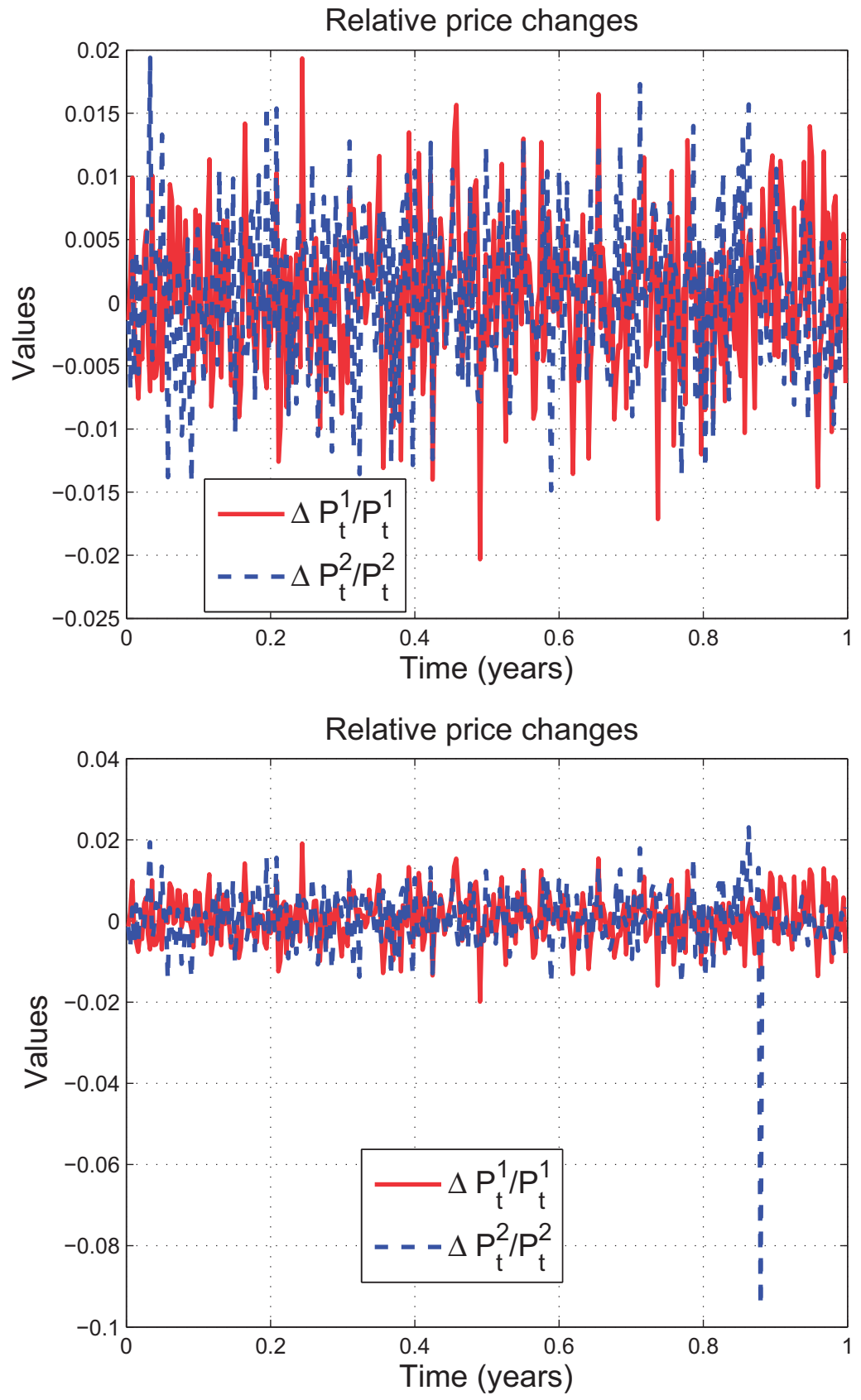

Figure 4

Relative price changes for the two assets under the same realization of shocks as in Figure 3

Top panel: Liquidity-based allocation strategy. Bottom panel: Fixed relative exposure strategy. 
requirements. However, empirical evidence provided by Gropp and Heider (2010) suggests that banks have stable capital structures at levels that are specific to individual banks, and typically their target leverage is well below the regulatory level.

More plausibly, regulators could create incentives for banks to operate more closely to a liquidity-based strategy, in the spirit of (5). Policies of this type are already in place: the newly imposed Basel III liquidity requirements (see Basel III (2013)) feature such a mechanism. One of the key reforms is the liquidity coverage ratio (LCR). This requires banks to maintain an adequate stock of high-quality liquid assets readily convertible into cash to meet liquidity needs over an acute stress scenario lasting 30 days. More specifically, it is imposed that the ratio between the stock of high quality assets and the total net cash outflows over the next 30 days be higher than one. To comply with the LCR requirement, banks would need to restructure the asset side of their balance sheets if their LCR is below one. This can be achieved, for instance, by increasing holdings of high rated domestic government and corporate bonds or residential mortgage-backed securities, while reducing exposure to more illiquid assets, thus moving toward a liquidity-based asset allocation strategy.

While our model does not provide conclusive guidance regarding the behavior of leverage targeting banks if LCR requirements are explicitly accounted for, our results suggest that it is beneficial for financial stability if banks hold liquid assets on their balance sheets. Extensions of the model accounting for asset purchases and lending of last resort would also be interesting. Such factors might contribute to reduce fire-sales externalities, but would also decrease banks' incentives to invest in liquid assets and instead push them to hold riskier and more illiquid assets on their balance sheets. The design of a comprehensive model in which this trade-off can be studied is however outside the scope of the present paper.

\section{Conclusions}

Leverage has been identified by financial regulators as one of the main causes of the financial crisis. Policy leaders have expressed concerns about the inadequate levels of capital in the financial system and focused attention on the leverage ratio. Meanwhile, empirical evidence suggests that banks tend to track a fixed leverage ratio. Our study addresses the effects on price contagion resulting from the presence of leverage targeting banks. The key outcome of our analysis is that the leverage targeting behavior can produce high fire-sales externalities and have a destabilizing effect, causing asset prices to become highly correlated, and sensitive to shocks. This happens because banks that track a fixed leverage ratio have an upward-sloping demand curve. In normal times, the downward-sloping demand curve of the nonbanking sector exerts a stabilizing force on asset prices. However, after sustained periods of growth in 
the banking sector, this force may no longer be sufficient to keep prices stable. Our analysis contributes to informing the currently active policy debate on leverage requirements. It provides support for policies aimed at creating incentives for banks to implement asset allocation strategies with higher exposure to liquid, rather than illiquid, assets.

\section{Appendix A. Nonzero Interest Rate}

This Appendix contains all of our mathematical results for the case in which the interest rate $r$ is not necessarily zero. The propositions stated in the main text then follow as special cases. In the setting of a nonzero interest rate, the cash-flow equation (1.2) is replaced by the following, where the additional term accounts for interest payments on existing debt.

$$
P_{t+\Delta t}^{k} \Delta Q_{t}^{k i}=\alpha_{t}^{k i}\left(\Delta R_{t}^{i}+\Delta D_{t}^{i}-r \Delta t D_{t}^{i}\right), \quad i=1, \ldots, N, \quad k=1, \ldots, K
$$

The following result gives the banks' demand curves in this setting. Proposition 1.1 is recovered by setting $r=0$.

Proposition 5.1 The $i$ :th bank's incremental demand for asset $k$ is given by

$$
\Delta Q_{t}^{k i}=\frac{\alpha_{t}^{k i}}{P_{t+\Delta t}^{k}}\left(\lambda_{i} Q_{t}^{i \top} \Delta P_{t}-\lambda_{i} A_{t}^{i \top} \mathbf{1} r \Delta t+\left(1+\lambda_{i}\right) \Delta R_{t}^{i}\right) .
$$

Proof Writing the cash-flow equation (5.1) in vector form yields

$$
\operatorname{Diag}\left(P_{t+\Delta t}\right) \Delta Q_{t}^{i}=\alpha_{t}^{i}\left(\Delta R_{t}^{i}+\Delta D_{t}^{i}-r \Delta t D_{t}^{i}\right) .
$$

For notational simplicity, let $L_{i}=\lambda_{i} /\left(1+\lambda_{i}\right)$, so that by the leverage equation (1.1) we have $D_{t}^{i}=L_{i} \mathbf{1}^{\top} A_{t}^{i}$. Substitute for $D_{t}^{i}$ and $D_{t+\Delta t}^{i}$ in the above equation to get

$$
\operatorname{Diag}\left(P_{t+\Delta t}\right) \Delta Q_{t}^{i}=\alpha_{t}^{i}\left(\Delta R_{t}^{i}+L_{i} \mathbf{1}^{\top} \Delta A_{t}^{i}-L_{i} r \Delta t \mathbf{1}^{\top} A_{t}^{i}\right) .
$$

Rearranging using the identity $\mathbf{1}^{\top} \Delta A_{t}^{i}=P_{t+\Delta t}^{\top} \Delta Q_{t}^{i}+Q_{t}^{i \top} \Delta P_{t}$ leads to

$$
\left(\operatorname{Diag}\left(P_{t+\Delta t}\right)-L_{i} \alpha_{t}^{i} P_{t+\Delta t}^{\top}\right) \Delta Q_{t}^{i}=\alpha_{t}^{i}\left(\Delta R_{t}^{i}+L_{i} Q_{t}^{i \top} \Delta P_{t}-L_{i} r \Delta t \mathbf{1}^{\top} A_{t}^{i}\right) .
$$

The matrix multiplying $\Delta Q_{t}^{i}$ can be inverted using the Sherman-Morrison formula. First, since $\mathbf{1}^{\top} \alpha_{t}^{i}=1$, we have

$$
1-L_{i} P_{t+\Delta t}^{\top} \operatorname{Diag}\left(P_{t+\Delta t}\right)^{-1} \alpha_{t}^{i}=1-L_{i} \mathbf{1}^{\top} \alpha_{t}^{i}=1-L_{i} \neq 0,
$$

so invertibility is guaranteed. The inverse is given by

$$
\operatorname{Diag}\left(P_{t+\Delta t}\right)^{-1}+\lambda_{i} \operatorname{Diag}\left(P_{t+\Delta t}\right)^{-1} \alpha_{t}^{i} P_{t+\Delta t}^{\top} \operatorname{Diag}\left(P_{t+\Delta t}\right)^{-1},
$$

which simplifies to $\operatorname{Diag}\left(P_{t+\Delta t}\right)^{-1}\left(I+\lambda_{i} \alpha_{t}^{i} \mathbf{1}^{\top}\right)$. From (5.3) we therefore obtain

$$
\begin{gathered}
\operatorname{Diag}\left(P_{t+\Delta t}\right) \Delta Q_{t}^{i}=\left(I+\lambda_{i} \alpha_{t}^{i} \mathbf{1}^{\top}\right) \alpha_{t}^{i}\left(\Delta R_{t}^{i}+L_{i} Q_{t}^{i \top} \Delta P_{t}-L_{i} r \Delta t \mathbf{1}^{\top} A_{t}^{i}\right) \\
=\left(1+\lambda_{i}\right) \alpha_{t}^{i}\left(\Delta R_{t}^{i}+L_{i} Q_{t}^{i \top} \Delta P_{t}-L_{i} r \Delta t \mathbf{1}^{\top} A_{t}^{i}\right),
\end{gathered}
$$

where the second equality uses the identity $\left(I+\lambda_{i} \alpha_{t}^{i} \mathbf{1}^{\top}\right) \alpha_{t}^{i}=\left(1+\lambda_{i}\right) \alpha_{t}^{i}$, which follows from $\mathbf{1}^{\top} \alpha_{t}^{i}=1$. The stated expression (1.3) now follows by noting that $\left(1+\lambda_{i}\right) L_{i}=\lambda_{i}$.

Next, we give the general version of Proposition 2.1, which is again obtained by setting $r=0$ below. 
Proposition 5.2 The cash-flow equation (5.1), the leverage equation (1.1), the external demand function (1.5), and the market clearing condition (2.1) imply that the dynamics of asset prices and asset holdings are given by

$$
\begin{aligned}
\frac{\Delta P_{t}}{P_{t}} & =\left(\boldsymbol{I}-\boldsymbol{S}_{t}\right)^{-1}\left\{\frac{\Delta Z_{t}}{P_{t}}+\sum_{i=1}^{N} \frac{\alpha_{t}^{i}}{\gamma \circ A_{t}^{\mathrm{nb}}}\left[\left(1+\lambda_{i}\right) \Delta R_{t}^{i}-\lambda_{i} A_{t}^{i \top} \mathbf{1} r \Delta t\right]\right\}, \\
\Delta A_{t}^{i} & =Q_{t}^{i} \circ \Delta P_{t}+\alpha_{t}^{i}\left(\lambda_{i} Q_{t}^{i \top} \Delta P_{t}-\lambda_{i} A_{t}^{i \top} \mathbf{1} r \Delta t+\left(1+\lambda_{i}\right) \Delta R_{t}^{i}\right), \\
\Delta A_{t}^{\mathrm{nb}} & =Q_{t}^{\mathrm{nb}} \circ\left(\gamma \circ \Delta Z_{t}-(\gamma-\mathbf{1}) \circ \Delta P_{t}\right),
\end{aligned}
$$

assuming that the matrix inverse exists.

Proof First, we use the market-clearing condition (2.1), and then the expressions (5.2) and (1.5) for the demand functions to get

$$
\begin{gathered}
0=P_{t+\Delta t} \circ \Delta Q_{t}^{k, \mathrm{n} b}+\sum_{i=1}^{N} P_{t+\Delta t} \circ \Delta Q_{t}^{i} \\
=\operatorname{Diag}\left(\gamma \circ Q_{t}^{\mathrm{nb}}\right)\left(\Delta Z_{t}-\Delta P_{t}\right)+\sum_{i=1}^{N} \alpha_{t}^{i}\left(\lambda_{i} Q_{t}^{i \top} \Delta P_{t}-\lambda_{i} A_{t}^{i \top} \mathbf{1} r \Delta t+\left(1+\lambda_{i}\right) \Delta R_{t}^{i}\right) .
\end{gathered}
$$

Multiplying from the left by $\operatorname{Diag}\left(\gamma \circ Q_{t}^{\text {nb }}\right)^{-1}$ and rearranging yields

$$
\left[\boldsymbol{I}-\sum_{i=1}^{N} \frac{\alpha_{t}^{i}}{\gamma \circ Q_{t}^{\mathrm{nb}}} \lambda_{i} Q_{t}^{i \top}\right] \Delta P_{t}=\Delta Z_{t}+\sum_{i=1}^{N} \frac{\alpha_{t}^{i}}{\gamma \circ Q_{t}^{\mathrm{nb}}}\left[\left(1+\lambda_{i}\right) \Delta R_{t}^{i}-\lambda_{i} A_{t}^{i \top} \mathbf{1} r \Delta t\right] .
$$

Noting that the left side is equal to

$$
\operatorname{Diag}\left(P_{t}\right)\left(\boldsymbol{I}-\boldsymbol{S}_{t}\right) \frac{\Delta P_{t}}{P_{t}},
$$

we simply multiply the equality (5.7) from the left by $\left(\boldsymbol{I}-\boldsymbol{S}_{t}\right)^{-1} \operatorname{Diag}\left(P_{t}\right)^{-1}$ to arrive at the stated price dynamics (5.4). Next, we have $\Delta A_{t}^{i}=Q_{t}^{i} \circ \Delta P_{t}+P_{t+\Delta t} \circ \Delta Q_{t}^{i}$. Inserting (5.2) into this expression yields (5.5). The expression (5.6) is obtained similarly, using (1.5) instead of (5.2).

\section{Appendix B. Proofs for Section 3}

Proof of Proposition 3.1 Under the stated assumptions, $\boldsymbol{S}_{t}$ is component-wise nonnegative. The lower bound is exactly the inequality $\max _{k} \boldsymbol{S}_{t}^{k k} \leq \rho\left(\boldsymbol{S}_{t}\right)$, which always holds for nonnegative matrices (Horn and Johnson, 1985, Corollary 8.1.20). The upper bound, call it $\beta$, satisfies $\boldsymbol{S}_{t} 1 \leq \backslash$ beta1, which implies $\rho\left(\boldsymbol{S}_{t}\right) \leq \mid$ beta by (Horn and Johnson, 1985, Corollary 8.1.29).

Proof of Equation (3.3) Combining the expression (2.2) for the elements of the systemicness matrix with the definition (3.2) of the liquidity-based allocation weights gives

$$
S_{t}^{k \ell}=\frac{\sum_{i=1}^{N} \lambda_{i} A_{t}^{\ell i}}{\sum_{j=1}^{K} \gamma_{j} A_{t}^{j, \mathrm{nb}} .}
$$


Hence, the $k$ th component of the vector $\boldsymbol{S}_{t} \mathbf{1}$ is

$$
\left(\boldsymbol{S}_{t} \mathbf{1}\right)_{k}=\sum_{\ell=1}^{K} S_{t}^{k \ell}=\frac{\sum_{i=1}^{N} \lambda_{i} \mathbf{1}^{\top} A_{t}^{i}}{\sum_{j=1}^{K} \gamma_{j} A_{t}^{j, \mathrm{nb}}} .
$$

Denote the right-hand side by $\bar{\rho}$. We have shown $\boldsymbol{S}_{t} \mathbf{1}=\bar{\rho} \mathbf{1}$, so that $\bar{\rho}$ is an eigenvalue with eigenvector 1. On the other hand, by combining the upper bound in Proposition 3.1 with the expression (3.2) for the liquidity-based allocation weights, we find

$$
\rho\left(\boldsymbol{S}_{t}\right) \leq \bar{\rho} .
$$

Since $\rho\left(\boldsymbol{S}_{t}\right)$ is the maximum eigenvalue modulus by definition, it follows that $\rho\left(\boldsymbol{S}_{t}\right)=\bar{\rho}$.

Proof of Proposition 3.2 Suppose by contradiction that the claim is false. Then, for all $k$, we have

$$
\frac{\sum_{i=1}^{N} \lambda_{i} 1^{\top} A_{t}^{i}}{\sum_{\ell=1}^{K} \gamma_{\ell} A_{t}^{\ell, \mathrm{nb}}}>\frac{\sum_{i=1}^{N} \lambda_{i} A_{t}^{k i}}{\gamma_{k} A_{t}^{k, \mathrm{nb}}}
$$

or, equivalently, $\gamma_{k} A_{t}^{k, \mathrm{nb}}\left(\sum_{i=1}^{N} \lambda_{i} 1^{\top} A_{t}^{i}\right)>\left(\sum_{\ell=1}^{K} \gamma_{\ell} A_{t}^{\ell, \mathrm{nb}}\right)\left(\sum_{i=1}^{N} \lambda_{i} A_{t}^{k i}\right)$ for all $k$. Summing both sides over $k$ yields

$$
\left(\sum_{k=1}^{N} \gamma_{k} A_{t}^{k, \mathrm{nb}}\right)\left(\sum_{i=1}^{N} \lambda_{i} 1^{\top} A_{t}^{i}\right)>\left(\sum_{\ell=1}^{K} \gamma_{\ell} A_{t}^{\ell, \mathrm{nb}}\right)\left(\sum_{i=1}^{N} \lambda_{i} 1^{\top} A_{t}^{i}\right),
$$

which is a contradiction since the left- and right-hand sides coincide. This proves the result.

\section{References}

Acharya, V., R. Engle, and M. Richardson. 2012. Capital shortfall: A new approach to ranking and regulating systemic risks. American Economic Review 102:59-64.

Acharya, V., L. Pedersen, T. Philippon, and M. Richardson. 2010. Measuring systemic risk. Working Paper, NYU.

Adrian, T., and N. Boyarchenko. 2013. Intermediary leverage cycles and financial stability. Staff Report No. 567.

Adrian, T., and M. K. Brunnermeier. 2011. Covar. National Bureau of Economic Research (17454).

Adrian, T., P. Colla, and H. S. Shin. 2012. Which financial frictions? Parsing the evidence from the financial crisis of 2007-09. NBER Macroeconomics Annual, 27.

Adrian, T., and H. S. Shin. 2008. Liquidity and financial contagion. Financial Stability Review-Special Issue on Liquidity, Banque de France, 11.

2010. Liquidity and leverage. Journal of Financial Intermediation 19:418-37.

2014. Procyclical leverage and value-at-risk. Review of Financial Studies 27:373-403.

Basel III. 2013. The liquidity coverage ratio and liquidity risk monitoring tools. Basel Committee on Banking Supervision.

Berger, A., R. DeYoung, M. Flannery, D. Lee, and O. Oztekin. 2008. How do large banking organizations manage their capital ratios? Journal of Financial Services Research 34:123-49. 
Brownless, C. T., and R. Engle. 2015. Srisk: A conditional capital shortfall index for systemic risk measurement. Working Paper, New York University.

Brunnermeier, M., and L. H. Pedersen. 2009. Market liquidity and funding liquidity. Review of Financial Studies 22:2201-38.

Chen, C., G. Iyengar, and C. Moallemi. 2013. An axiomatic approach to systemic risk. Management Science 6:1373-88.

2014. Asset price-based contagion models for systemic risk. Working Paper, Columbia University.

Coval, J., and E. Stafford. 2007. Asset fire sales (and purchases) in equity markets. Journal of Financial Economics $86: 479-512$.

Duarte, F., and T. Eisenbach. 2013. Fire-sale spillovers and systemic risk. Federal Reserve Bank of New York Staff Reports, 645.

Ellul, A., C. Jotikasthira, and C. T. Lundblad. 2011. Regulatory pressure and fire sales in the corporate bond market. Journal of Financial Economics 101:596-620.

European Commission. 2012. Non-bank financial institutions: Assessments of their impact on the stability of the financial system. Economic Papers, 472, November 2012.

Greenlaw, D., J. Hatzius, A. Kashyap, and H. S. Shin. 2008. Leveraged losses: Lessons from the mortgage market meltdown. Proceedings of the U.S. Monetary Policy Forum.

Greenwood, R., A. Landier, and A. Thesmar. 2014. Vulnerable banks. Journal of Financial Economics, Forthcoming.

Gropp, R., and F. Heider. 2010. The determinants of bank capital structure. Review of Finance 14:587-622.

Horn, R. A., and C. A. Johnson. 1985. Matrix analysis. Cambridge: Cambridge University Press.

Jotikasthira, C., C. T. Lundblad, and T. Ramadorai. 2012. Asset fire sales and purchases and the international transmission of funding shocks. Journal of Finance 67:2015-50.

Shleifer, A., and R. Vishny. 1992. Liquidation values and debt capacity: A market equilibrium approach. Journal of Finance 47:1343-66.

2011. Fire sales in finance and macroeconomics. Journal of Economic Perspectives 25:29-48. 